\title{
10 \\ Strategic studies in practice: A South-East Asian perspective
}

\author{
Peter Ho
}

I begin this chapter with two disclaimers. First, I am not an expert on strategic studies. Second, I do not think that a singular and monolithic South-East Asian perspective on strategic studies exists. In this regard, as far as I am aware, in South-East Asia, there is only one institute that is properly focused on the full range of strategic studies, and that is Singapore's S. Rajaratnam School of International Studies, or RSIS. ${ }^{1}$

\section{A personal history}

My encounters with strategic studies have been tangential. My first encounter occurred when I was in military service and a student at our command and staff course in Singapore. The course introduced me to thinkers like Mahan, Douhet, Liddell Hart and, of course, Clausewitz and Sun Tzu. We studied strategic concepts like nuclear deterrence, great

1 The S. Rajaratnam School of International Studies (RSIS) was established in January 2007 as an autonomous school within Singapore's Nanyang Technological University. Known as the Institute of Defence and Strategic Studies (IDSS) when it was established in July 1996, RSIS's mission is to be a leading research and graduate teaching institution in strategic and international affairs in the Asia-Pacific. 
power dynamics, liberation ideologies, Marxism-Leninism, Maoism, revolutionary warfare, counter-insurgency warfare, united front tactics, guerrilla warfare and so on.

For good reason, strategic studies were taught in tandem with military history. The orientation then, as now, was, not surprisingly, focused on the region, so the Malayan Campaign and the Malayan Emergency were dissected in some detail for the lessons that could be gleaned from these two upheavals. We were fortunate to have obtained the original manuscript of Masanobu Tsuji's detailed account of the planning and execution of the Japanese invasion of Malaya. Tsuji was a colonel in the Japanese Army and, as a member of General Yamashita's staff, planned the invasion.

Strategic studies and military history opened up an entirely new world for me. They provided insights into the past and, more importantly, an understanding of present issues - such as the Cold War, which was then still the central geopolitical fact of life.

But over time, I lost my currency in the vocabulary and the details, even though I have retained my understanding of the broad concepts. Having said that, in my time, Singapore luckily faced no conflict to test my understanding of these ideas and concepts. Luckily for me too, I was never put to the test. I think I would have been proven to be not very competent-certainly in the academic minutiae and probably as a military commander.

Some years after I completed the command and staff course at Singapore's Goh Keng Swee Command and Staff College, I led a review of the college's syllabi. The review, not surprisingly, asserted the importance of strategic studies and military history. So not only did strategic studies and military history remain at the core of the various programs run by the command and staff college, but a Department of Strategic Studies was also established.

Later on, in 1997, teaching of strategic studies and military history was outsourced to the new Institute of Defence and Strategic Studies (IDSS), which became a full school-RSIS-10 years later in 2007. This provided the Command and Staff College access to a team of experts whose primary business was strategic studies and military history, thus enhancing the quality of teaching in this important area. In return, it anchored strategic studies as a core capability of IDSS/RSIS. 


\section{Why strategic studies?}

At this point, it might be useful to ask a basic question: why is strategic studies important? I discovered its value later on in civilian life when I worked on plans and policy in the Ministry of Defence (Singapore), during my postings to the Ministry of Foreign Affairs, and when I was in charge of National Security and Intelligence Coordination (a department under the Prime Minister's Office).

It was in these positions that the concepts and constructs embedded in strategic studies really came alive for me. They provided an important foundation to help me to understand the world, discover the drivers of grand strategy, uncover the impulses of foreign policy and develop an instinct about how nations and governments respond to challenges and how they interact with one another. They helped me to connect strategy to operations and plans, and to frame decisions in their conceptual, intellectual, historical and ideological contexts.

But I also found out that, as a discipline, strategic studies are largely based on hindsight and historical insight, while my experience in planning and policy-making taught me that things never follow a predictable trajectory, especially in the medium to long term.

\section{Strategic surprise}

When I became a planner and a policy officer in the Ministry of Defence in the early 1980s, it would have been difficult for anyone to grasp the concept of transnational terrorism that today preoccupies defence and national security planners and policy-makers. We were still in the throes of the Cold War, although hindsight now tells us that the war was then already waning. In those days, the 'revolution in military affairs' (RMA) ${ }^{2}$ and cyber warfare were concepts that we could only dimly understand. Today, they have become part of mainstream thinking.

2 'According to Andrew Marshall, director of the Office of Net Assessments in the Office of the Secretary of Defense: "A revolution in military affairs (RMA) is a major change in the nature of warfare brought about by the innovative application of new technologies which, combined with dramatic changes in military doctrine and operational and organisational concepts, fundamentally alters the character and conduct of military operations."' Lothar Ibrugger, 'The revolution in military affairs', NATO Parliamentary Assembly special report, November 1998, www.iwar.org.uk/rma/ resources/nato/ar299stc-e.html (retrieved 21 January 2018). 
Indeed, one of the foremost challenges facing anyone in the business of planning or policy-making is the challenge of strategic surprise.

Most of us have heard of black swans, a term coined by Nassim Nicholas Taleb. ${ }^{3}$ They are rare, hard-to-predict events that have a large, gamechanging impact. Later on, in 2002, the then US Secretary of Defense, Donald Rumsfeld, introduced us to a close relative of the black swan, the unknown unknown. He said:

There are known knowns. These are things we know we know. We also know there are known unknowns. That is to say we know that there are some things we do not know. But there are also unknown unknowns, the ones we don't know we don't know. ${ }^{4}$

When he said this, a lot of people poked fun at him. But notions of known unknowns and unknown unknowns reflect a serious concept. If you are in the business of defence, or if you are in the military, you ought to understand what known unknowns are and what unknown unknowns are, because you are going to be surprised by both every now and then. And it helps to understand the difference between them.

In Singapore, we have had encounters with black swans and unknown unknowns in recent years: the Asian Financial Crisis of 1997-98; 9/11; the uncovering of the Jemaah Islamiyah terrorist network in December 2001; the global economic and financial crisis of 2008-09; the Arab Spring; the rise of ISIS or Daesh; Brexit; and so on.

The frequency of such strategic shocks seems to be increasing, and the amplitude of their impact is growing. Lenin explained why when he said, 'Everything is connected to everything else'. A few hundred years earlier, Leonardo da Vinci had said, 'Everything connects to everything else'. Both might even have been aware that the ancient Chinese philosopher Lao Tzu had made much the same observation some 1,500 years ago, that 'everything is connected and everything relates to each other'.

3 A black swan is a metaphor for an event that comes as a surprise, has a major impact and is often rationalised after the fact with the benefit of hindsight. The theory was developed by Nassim Nicholas Taleb and described in his eponymous bestseller The Black Swan: The Impact of the Highly Improbable, Random House, New York, 2010.

4 Donald Rumsfeld, the then US Secretary of Defense, responding to a question at a Department of Defense (DoD) news briefing on 12 February 2002 about the lack of evidence linking the Iraqi Government with the supply of weapons of mass destruction to terrorist groups. 'DoD news briefing-Secretary Rumsfeld and Gen. Myers', US Department of Defense, archive.defense.gov/ transcripts/transcript.aspx?transcriptid=2636 (retrieved 22 September 2016). 
Globalisation increases and intensifies these connections, as does the Internet. In such a connected world, what happens in one part of the world is going to affect other parts of the world-the so-called butterfly effect, which postulates that the flap of a butterfly's wings in Brazil can set off a tornado in Texas. ${ }^{5}$ The butterfly effect is the concept that small causes can have large effects. Events and actions in different parts interact with each other in complex, non-linear ways to produce effects that are difficult to determine ex ante. Instead, their behaviour is emergent. This is the defining characteristic of a complex system that today forms the basis of the new science of complexity. ${ }^{6}$

In December 2010, Mohamed Bouazizi, a street vendor in Tunis, set himself alight. He was upset by the lack of support from the Tunisian authorities. It was a terminal protest because he died from the selfimmolation. But that single act-a single event-triggered the Arab Spring. The consequences were dramatic. Governments collapsed in Tunisia, Egypt, Libya and Yemen. Governments changed in Kuwait, Bahrain and Oman. A civil war broke out in Syria, and it is still raging six years after Bouazizi killed himself. It can be argued that these events set the stage for the rise of the Islamic State or ISIS or Daesh.

The most imaginative novelist could not have written the script for the Arab Spring. The Danish philosopher Søren Kierkegaard once said, 'Life is understood backwards, but it must be lived forwards'. ${ }^{7}$ Encapsulated in this profound statement is the concept of retrospective coherence, otherwise known as hindsight. The current state of affairs always makes logical sense when you can look backwards in time. That is hindsight, and it helps us to understand why something happened. That is why strategic studies and military history are so useful.

5 Edward Norton Lorenz, an American mathematician, meteorologist and pioneer of chaos theory, introduced this concept in 1972. See Peter Dizikes, 'When the butterfly effect took flight', MIT Technology Review, 22 February 2011, www.technologyreview.com/s/422809/when-the-butterflyeffect-took-flight/ (retrieved 21 January 2018).

6 Kevin Oliver, 'Climate dynamics', University of Southampton School of Ocean and Earth Science lecture slides, undated, slideplayer.com/slide/10423511/ (retrieved 21 January 2018). 'Complexity science is the scientific study of complex systems, systems with many parts that interact to produce global behaviour that cannot easily be explained in terms of interactions between the individual constituent elements.'

7 Søren Kierkegaard, Journalen JJ:167 (1843), Søren Kierkegaards Skrifter, volume 18, Søren Kierkegaard Research Center, Copenhagen, 1997, p. 306. 
But hindsight is not necessarily able to tell you what is going to happen when you look forward in time. The current pattern is logical, but it is only one of many patterns that could have been formed, any one of which would have been equally logical. Where we are today is path-dependent, ${ }^{8}$ and arises because of complexity. That is the problem. We cannot predict the future.

Singapore's founding prime minister, the late Mr Lee Kuan Yew, said, 'The past was not preordained, nor is the future. There are as many unexpected problems ahead as there were in the past'. ${ }^{9}$ It sounds like a truism, but it is the reality that governments have to deal with.

\section{The black elephant}

At this point, I would like to introduce another occupant of my menagerie of strategic surprise, the black elephant.

What is a black elephant? It is a cross between a black swan and the elephant in the room. The black elephant is a problem that is actually visible to everyone-the proverbial elephant in the room-but no one wants to deal with it so they pretend it is not there. It is seen to be an improbable event when actually it is not. When the problem blows up, everyone feigns surprise and shock, behaving as if it were a black swan.

All human beings have blind spots. The tendency of the human mind is to underestimate sudden crises, whether because of their own cognitive biases or because it is inconvenient to admit to the obvious. ${ }^{10}$ So initially, through hesitation and until events reach crisis proportions, nobody takes any action. This can lead to military failure-for example, the Japanese attack on Pearl Harbor in 1941 and the Yom Kippur War in 1973.

8 'Path dependence explains how the set of decisions one faces for any given circumstance is limited by the decisions one has made in the past, even though past circumstances may no longer be relevant.' From Jay Barney and William Hesterly, Strategic Management and Competitive Advantage: Concepts, 2nd edn, 2007, Pearson, Upper Saddle River.

9 The then Prime Minister of Singapore, Lee Kuan Yew, speaking at his 60th birthday dinner on 16 September 1983.

10 Cognitive bias: 'Systematic error in judgment and decision-making common to all human beings which can be due to cognitive limitations, motivational factors, and/or adaptations to natural environments.' (A. Wilke and R. Mata, 'Cognitive bias', Encyclopedia of Human Behavior, 2nd edn, vol. 1, ed. V.S. Ramachandran, Academic Press, Cambridge, MA, 2012). 
ISIS is arguably a black elephant. Then US President Barack Obama admitted in September 2014, 'The United States underestimated the threat posed by ISIS fighters in Syria and overestimated the effectiveness of the security forces in Iraq'. ${ }^{11}$ Most recently, we were astonished to learn that the Treasury in the United Kingdom had made no contingency plans for Brexit. ${ }^{12}$ Neither had the British armed forces. In my view, these stand as examples of black elephants in our midst.

\section{Strategic surprise and governance}

One of the pioneer members of the Singapore Cabinet, Mr S. Rajaratnam, was a very forward-looking person with a strategic outlook. In 1979, he said:

There are practical men who maintain that such speculations [thinking about the future] are a waste of time. And they have no bearing at all on solutions to immediate day-to-day problems. This may have been so in earlier periods of history when changes were few and minute, and were spread over decades and centuries. But because we are not only living in a world of accelerating changes but also of changes which are global in scope and which permeate almost all aspects of human activity ... and since change is about the future, then only a future-oriented society can cope with the problems of the 21 st century. ${ }^{13}$

$\mathrm{Mr}$ Rajaratnam was talking about the operating environment of a globalised world in which the pace of change is accelerating. How do we cope with that? We must begin to learn to think systematically about a future that is inherently volatile, uncertain, complex and ambiguous (VUCA) just as we think about the past that is known or knowable.

Anticipating and preparing for change is a profound and critical strategic capability for any government, particularly for military and defence establishments but more generally for all parts of government. Here lies the conundrum that all planners and policy-makers face. How do you

11 President Barack Obama in '60 Minutes' interview on CBS, 26 September 2014, broadcast 28 September 2014, www.cbsnews.com/news/obama-u-s-underestimated-rise-of-isis-in-iraq-and-syria/ (retrieved 30 January 2018).

12 Gemma Tetlow, 'Treasury made no plans for Brexit, says new head, Tom Scholar', Financial Times, 7 July 2016.

13 Speech by S. Rajaratnam, Minister for Foreign Affairs, 'Singapore into the 21st century', seminar, Singapore Association for the Advancement of Science, Singapore Science Centre, 20 December 1979. 
make plans and policies for the long term, knowing that changes in the operating environment are likely to occur within a shorter time frame and that they will inevitably affect or even negate these plans? You make certain assumptions when you launch a big capital project such as a warship or an aircraft. But there inevitably will be changes in technology and the strategic environment. How do you factor these changes, many of which cannot be foreseen, into the planning for such projects that might have life spans for capital platforms of maybe 20, 30 or 40 years?

There is no way we can predict the future. If we could, many of us would be out of jobs. But we can adopt methods and processes that help us reduce the frequency of strategic shock and reduce its amplitude or intensity when the inevitable shock occurs. Strategic studies have an important role to play in each of these tasks.

\section{Scenario planning}

There are foresight methodologies - ways to think about the future systematically and ways that help to overcome some of our latent biases and inherent cognitive constraints. One of them is the famous scenario planning method, which was developed and pioneered by the oil giant Shell. In fact, in 2012, Shell commemorated 40 years of scenario planning. ${ }^{14}$ Shell famously avoided the impact of the oil shock in the 1970s because of scenario planning. But I have not seen much evidence that strategic studies have adopted such tools, perhaps because these foresight methods are too unconventional and maybe because they are perceived to lack academic respectability.

Governments are less constrained, however, because they have to deal with the real world and their imperative is to deliver results. In Singapore, the Ministry of Defence made it an imperative to find ways to better anticipate changes in technology and the operating environment. In the late 1980s, it started using Shell's scenario planning techniques. Then, in 1991, encouraged by Ministry of Defence's positive experiences with scenario planning, a Scenario Planning Office (now called the Strategic

14 Shell has been doing scenario planning since the 1970s to help its leaders explore ways forward and make better decisions. Scenarios ask 'what if?' questions, encouraging leaders to consider events that might be only remote possibilities, to stretch their thinking. Shell scenarios also help governments, academia and business to understand possibilities and uncertainties ahead. 
Policy Office) was set up in the Prime Minister's Office to apply the technique to issues affecting the entire government, not just the defence and security agencies.

Today, scenario planning is a key part of the Singapore Government's strategic planning process. National-level scenario planning exercises are run every few years and are even incorporated into the annual budget cycle. The resultant scenarios are used by ministries and agencies as a base reference for their own strategic planning. Apart from these efforts, which deal with issues on a national scale, focused scenario studies are also carried out on specific issues like climate change or when significant geopolitical change seems imminent.

In the Singapore experience, we have discovered that when scenarios are well crafted and articulate imaginative yet plausible ways in which the future could evolve, planners and policy-makers will move out of their comfort zones, begin to think the unthinkable, and more willingly explore fresh strategies. Scenario planning helps to inculcate an 'anticipatory mindset' in planners and policy-makers so that they instinctively raise 'what if' questions on the issues they deal with.

\section{Beyond scenario planning}

Notwithstanding these benefits, scenario planning also has its limitations. Scenarios alone cannot adequately reflect the complexity of the operating environment. Scenario planning also undervalues the impact of the irrational on future outcomes and, unfortunately, is not very useful in locating the black swans and the unknown unknowns. The Nobel laureate, economist and strategic thinker Thomas Schelling explained, 'One thing a person cannot do, no matter how rigorous his analysis, or heroic his imagination, is to draw up a list of things that would never occur to him'.

We have adopted other tools to address this deficiency in Singapore, even if partially. While scenario planning remains the base, a wider range of foresight tools, such as 'horizon scanning', 'backcasting' and 'causallayered analysis', are now deployed. These tools are collectively referred to as Scenario Planning Plus (SP+). They help planners to uncover and discover some- but certainly not all—of the black swans and unknown unknowns lurking beyond the horizon. 
Horizon scanning ${ }^{15}$ tries to identify the big game-changers by looking for emerging issues and trends and delving into them to see where the threats and opportunities are.

What are the big game-changers now? Some of them are to be found in the current wave of innovation taking place in information technology. This is not only about big data and data analytics. It also includes the Internet of Things, cloud computing, drones, robotics and 3D printing (also known as additive manufacturing).

There have also been significant innovations in other sectors. The shale gas revolution created by fracking technology is part of the reason why oil prices are so low and why the United States is a net exporter of energy. Until recently, many ignored fracking, associating it solely with its potentially negative environmental impact. However, in hindsight, it is clear that this technology has been beneficially disruptive. Massive reserves of shale gas can now be extracted from the ground in the United States through fracking.

But such disruption is not just about innovation and opportunity. There is also a substantial potential downside. Serious people like Bill Gates, Stephen Hawking and Elon Musk have warned that artificial intelligence might pose an existential risk.

Cyber threats are now understood to be very serious. Two years ago, and just a few years after a sophisticated computer worm called Stuxnet was deployed to attack uranium enrichment centrifuges in the Iranian nuclear facility at Natanz, Iranian hackers infiltrated the control system of a small community dam less than 20 miles from New York City. Last year, three power grids in Ukraine were brought down by hackers using techniques similar to Stuxnet. But unlike in a traditional war, it is sometimes difficult to know where or even whether an opponent has struck.

Earlier this year, thieves siphoned US\$81 million from Bangladesh Bank in a sophisticated cyber heist. This was neither the first time nor the last.

15 'Horizon scanning (or environmental scanning) is the systematic process of picking up weak signals and trends and monitor driving forces, potential discontinuities and emerging issues from regular scanning of diverse information sources.' Centre for Strategic Futures and Civil Service College, 'Foresight: A glossary', Singapore, Centre for Strategic Futures, Public Service Division, Civil Service College, undated, www.csf.gov.sg/docs/default-source/default-document-library/csfcsc_foresight--a-glossary.pdf (accessed 18 June 2018). 
With artificial intelligence, drones can fly on pre-programmed routes and might even be able to choose their own targets. Newsweek declared, with some hyperbole, 'Once drones get artificial intelligence, they'll rule the world'. ${ }^{16}$

To top all this off, we see a growing ease of raising money for the new products from technological innovation. Crowdsourcing also made Defense Advanced Research Projects Agency's War Vehicle prototyping process five times faster. Crowdsourcing means that a terrorist can apply online and receive what amounts to a certification to kill.

There are other big issues. Demographics is a perennial. Water is another. Many countries are going to face water shortages because they have carelessly drained their water tables. In other words, they have used up a non-renewable resource: underground water. Furthermore, many other countries are now facing the effects of climate change, such as changing weather patterns disruptions to rainfall. The resulting water shortages are not mere inconveniences. They are an issue of survival and therefore have huge security and strategic implications.

Such emerging strategic issues have the potential to become gamechangers. The question is which ones should we focus on. Which ones are going to evolve into big challenges and be big opportunities? Which others will fizzle out? Strategic studies, complemented by scenario planning and other foresight techniques, can help us to develop a deeper understanding of such issues and to separate the existential from the merely inconvenient.

\section{Singapore's Centre for Strategic Futures}

In 2009, the Singapore Government set up the Centre for Strategic Futures (CSF) ${ }^{17}$ a think tank that promotes a whole-of-government approach to strategic planning. It identifies, adapts and develops foresight and futures thinking concepts and tools for the SP+toolbox, as well as analysing emerging issues for the Singapore Government. Although a

16 Kevin Maney, 'Once drones get artificial intelligence, they'll rule the world', Newsweek, 4 September 2016.

17 CSF's mission is to position the Singapore Government to navigate emerging strategic challenges and harness potential opportunities by building capacities, mind sets, expertise and tools for strategic anticipation and risk management; developing insights into future trends, discontinuities and strategic surprises; and communicating insights to decision-makers for informed policy planning. 
small outfit, the CSF is a catalyst for better foresight and futures thinking in the government and its agencies. Since the establishment of the CSF, several ministries and agencies of the Singapore Government have set up their own foresight or futures units. Giving a small group of people the latitude and the bandwidth to think systematically about the future is going some way to reducing the frequency of strategic surprise and mitigating the impact of such shocks.

\section{Wicked problems and complexity}

This growing network of foresight units has helped Singapore to deal, albeit imperfectly, with wicked problems, ${ }^{18}$ a term coined by design theorists Horst Rittel and Melvin Webber. Wicked problems are highly complex. Their causes and other influencing factors cannot easily be determined. Furthermore, they have multiple stakeholders who see these problems from different perspectives and who have divergent goals. This means there are no immediate or obvious solutions because nobody can agree on what the problems are in the first place, never mind what the solutions are.

Crises are usually wicked problems. Terrorism is a particularly wicked problem. Some of you might be surprised by this assertion because you would think that all of us want to get rid of terrorism-except of course the terrorists. But even if everyone agreed on how to distinguish terrorists from legitimate freedom fighters, and there was consensus that terrorism should be banished, it is not clear that the policy prescriptions would gain universal acceptance. If it were the case, then terrorism would not be the persistent problem that it is today and ISIS would not be such a serious threat.

We mostly work in organisations that respect hierarchy. This is how human systems work. But in a wicked problem where there are multiple stakeholders, more likely than not, there will be different organisations managing only parts of the larger problem. It should be an imperative

18 'A wicked problem that is difficult or impossible to solve because of incomplete, contradictory and changing requirements that are often difficult to recognize. The use of term "wicked" here has come to denote resistance to resolution, rather than evil.' ('Rhetorical terms', in Writing Across the Curriculum, Appalachian State University, undated, wac.appstate.edu/wac-glossary-terms/generalwriting-terms/d-rhetorical-terms (retrieved 21 January 2018, emphasis in original)). 
to be able to bring these different organisations together to address the wicked problem in its totality. In Singapore, we call this the 'whole-ofgovernment' approach.

Tackling the threat of Jemaah Islamiyah $(\mathrm{JI})^{19}$ has been a wicked problem for Singapore. It is not just about removing the immediate threat that the JI posed to Singapore's security. It also requires engaging multiple stakeholders, including community groups. It means engaging the private sector to assist in developing protective systems, processes and infrastructure. This approach clearly needs not just many agencies of government coming together but also bringing in the people and the private sectors. In a way, it is not just a 'whole-of-government ${ }^{20}$ approach but also a 'whole-of-nation' effort. The Singapore approach is to fight the JI network with a 'whole-of-nation' network. This is because JI poses a multidimensional threat that requires collaboration not only among security agencies but also social agencies with oversight of issues affecting local communities. Recently, the Singapore Government introduced the SGSecure movement, which involves bringing together multiple sectors and players to collaborate and coordinate against terrorist threats.

In the context of strategic studies, efforts to understand our complex world often rely on an assumption: that what is complex can be reduced to simpler subsets that are easier to evaluate and that when reaggregated will produce results that approximate the real world.

This approach is reductionism. ${ }^{21}$ Thomas Hobbes, one of the founders of modern political philosophy, argued that all phenomena, including human activity, could be reduced to bodies in motion and their interactions. This assumption gave birth to modern science. It led to the tendency to dissect the world and to favour explanations framed at the lowest level of scale. It is rooted in the belief that complex phenomena can be analysed in component-and simpler-parts. The assumption is that after these

19 JI is a South-East Asian militant Islamist terrorist group dedicated to the establishment of an Islamic caliphate in South-East Asia. JI was responsible for the Bali bombings on 12 October 2002.

20 'A term used in the Singapore Government to describe a networked approach to governance, where officers in different parts of government are able to overcome intra-government differences, e.g. differences in individual agency priorities and tackle problems as a coherent and coordinated whole.' (Centre for Strategic Futures and Civil Service College, 'Foresight: A glossary'.)

21 The practice of analysing and describing a complex phenomenon in terms of its simple or fundamental constituents. 
parts have been analysed separately, it is then possible to understand the properties of the whole in terms of the properties and the interactions of these components.

But despite the enormous importance of this approach, it gives the false impression that investigating the features of things at a holistic level is less informative than investigating the properties of the components. I would argue that strategic studies have tended towards the reductionist approach rather than looking at situations in a more holistic manner.

\section{Net assessments}

A way to offset the problems inherent in the reductionist approach is to employ the net assessment approach, which is done very well in the Australian Office of National Assessments. In many ways, the net assessment approach, pioneered by the US Department of Defense's Office of Net Assessment, which was headed for many years by the legendary Andrew Marshall, is analogous to the 'whole-of-government' approach.

Net assessment ${ }^{22}$ acknowledges that strategic interactions are shaped by the complex sprawling organisations that break big (and wicked) problems into manageable smaller ones. For example, one of the basic ways national security problems are broken down is departmentally between the military and the civilian intelligence community. Each jealously guards its role, and each is concerned about not revealing information that might help an opponent (also known as the doctrine of 'need to know').

This compartmentalisation has had a significant influence on strategy. Problems can be broken down in different ways. For example, an obvious question to ask is whether the military and the civilian intelligence agencies look at an opponent in the same way. Do they see trends similarly?

Such compartmentalisation creates a need for integration. At some point, information from these agencies has to be put together. But while many people assume that this happens automatically, those with a grasp of net

22 Adapted from Paul Bracken, 'Net assessment: A practical guide', Parameters, Spring 2006, pp. 90-100, strategicstudiesinstitute.army.mil/pubs/parameters/articles/06spring/bracken. htm (retrieved 13 March 2018). 
assessment — or of organisational behaviour-understand that nothing is automatic in big organisations, particularly if it involves sharing of information horizontally across vertical silos.

In net assessment, the imperative and the discipline is for information from all sources-and across disciplines - to be shared and evaluated holistically so that complex situations are studied as a whole and not in their parts. This approach helps connect the dots. By thinking broadly, by considering how different events, drivers and agents interact with each other, we can see the larger picture and obtain a better fix on the possible outcomes. In responding to wicked problems, such an approach is not just desirable—it is absolutely critical.

\section{Interdisciplinary thinking}

Net assessment and horizon scanning all require the ability to look at situations holistically. This is important because, as many have said, everything is connected to everything else. We will not see the wood for the trees if we look at each issue from a narrow perspective.

So this is also an argument for strategic studies to move beyond its traditional focus on politics and security and to enlarge its view of the world to see how economics, demographics, societal issues and issues of environment and of technology interact with each other to produce the complexities of the operating environment, a complexity that generates wicked problems, black swans and unknown unknowns. Strategic studies should move into a more interdisciplinary approach rather than study things in their separate domains. It is a counter-reductionist approach. In a research or an academic setting of strategic studies, this approach means that silos should be collapsed in favour of interdisciplinary collaboration.

But it is hard to counter the deep instinct in academia to focus on a single discipline bred out of centuries of reductionism and instead to move towards interdisciplinary collaboration. After all, there are Nobel Prizes for chemistry, physics, economics and medicine, but none for interdisciplinary collaboration. 
Nonetheless, interdisciplinary collaboration is imperative for solving the big challenges of today in science and technology, the social sciences, the economy, urbanisation and the environment. Why not in geopolitics, geostrategy and geoeconomics?

\section{Competing and complementary geographies}

As a penultimate point, I would like to return to the question of whether a South-East Asian perspective exists by pointing out that there is a difference in how people look at issues.

In his study of cultures, The Geography of Thought, ${ }^{23}$ Richard Nisbett identified a major cognitive difference between Western and Asianincluding South-East Asian-cultures. At the risk of oversimplification, after looking at a picture of, say, a horse, Westerners tend to remember the horse. But Asians (including of course South-East Asians) would also recall the background, whether there were clouds in the sky and whether the grass was green. The question is whether strategic studies can normalise this difference, perhaps by taking a more holistic, interdisciplinary and geographically diverse approach. In so doing, the discipline could create a better and a common understanding of the big challenges and issues facing the world.

\section{Conclusion}

Good plans and policies acknowledge the uncertainties and complexities of the operating environment. Strategic studies should likewise acknowledge these uncertainties and complexities to embrace tools of foresight and futures thinking and look at issues holistically. From these they can derive new insights that can help to inform the work of planners and policy-makers.

23 Richard E. Nisbett, The Geography of Thought: How Asians and Westerners Think Differently ... and Why, Free Press, New York, 2003. 
This text is taken from New Directions in Strategic Thinking 2.0:

ANU Strategic \& Defence Studies Centre's Golden Anniversary

Conference Proceedings, edited by Dr Russell W. Glenn, published 2018 by ANU Press, The Australian National University, Canberra, Australia. 